\title{
PERLINDUNGAN HUKUM BAGI MASYARAKAT TERHADAP PENGELOLAAN LIMBAH RUMAH POTONG HEWAN DI INDONESIA
}

\section{LEGAL PROTECTION FOR THE COMMUNITY AGAINST THE MANAGEMENT OF SLAUGHTERHOUSE WASTE IN INDONESIA}

\author{
Irnawati \\ Universitas PGRI Adi Buana Surabaya \\ irna15@unipasby.ac.id \\ Rhenny Ratnawati \\ Universitas PGRI Adi Buana Surabaya \\ ratnawati@unipasby.ac.id
}

\begin{abstract}
Abstrak
Tujuan dari penulisan artikel ini adalah memahami perlindungan hukum bagi masyarakat terhadap pengelolaan limbah rumah potong hewan di Indonesia. Limbah pengelolaan rumah potong hewan merupakan limbah yang dihasilkan dari proses pemotongan dan apabila tidak dikelola dengan baik akan menimbulkan dampak bagi lingkungan hidup di sekitar. Pencemaran terhadap pengelolaan limbah rumah potong hewan dapat terjadi jika tidak dilakukan pengelolaan secara benar. Metode pendekatan penelitian adalah yuridis normatif. Hasil penelitian memberikan jawaban bahwasanya perlindungan hukum terhadap masyarakat adalah hal yang mendasar untuk diakomodir oleh pemerintah sekitar. Pengelolaan limbah secara prosedur merupakan hal mutlak yang dilakukan oleh negara untuk menjamin kelangsungan hidup masyarakat secara baik di Indonesia.
\end{abstract}

Kata Kunci : perlindungan hukum, masyarakat, pengelolaan limbah, rumah potong hewan

\begin{abstract}
The purpose of writing this article is to understand the legal protection for people against the management of slaughterhouse waste in Indonesia. Animal slaughterhouse management waste is waste resulting from the cutting process and if not managed properly will have an impact on the surrounding environment. Pollution of animal slaughterhouse waste management can occur if not properly managed. The method of approaching research is normative juridical. The results of the study provide an answer that the protection of the law against the community is a fundamental thing to be accommodated by the surrounding government. Waste management is an absolute thing done by the state to ensure the good survival of the people in Indonesia.
\end{abstract}

Keywords : legal protection, community, waste management, slaughterhouse 


\section{A. Pendahuluan}

Pada dasarnya setiap manusia terlahir sebagai makhluk ciptaan Tuhan Yang Maha Esa (YME) secara kodrati mendapatkan hak dasar yaitu kebebasan, hak hidup, hak untuk dilindungi, dan hak lainnya. ${ }^{1}$ Perlindungan hukum yang diperoleh bukan hanya diwujudkan adaptif dan fleksibel melainkan prediktif dan antisipatif. ${ }^{2}$ Perlindungan hukum mutlak diperoleh karena hak setiap manusia. Berdasarkan perkembangan di lapangan, perlindungan hukum masih belum menjangkau aspek tertentu, termasuk pengelolaan limbah rumah potong hewan di Indonesia pada umumnya dan di Surabaya pada khususnya.

Berdasarkan data Direktori Perusahaan Pertanian Rumah Potong Hewan (RPH), dan Tempat Pemotongan Hewan (TPH) 2019, bahwasanya jumlah RPH dan DNRT di Indonesia yaitu 1.331 yang tersebar di 34 provinsi. Hampir 40 persen RPH/TPH terdapat di Pulau Jawa adalah sebanyak 514 RPH/TPH,

\footnotetext{
${ }^{1}$ Zainal Arifin Hoesein, Kekuasaan Kehakiman di Indonesia : Sejarah, Kedudukan, Fungsi dan Pelaksanaan Kekuasaan Kehakiman dalam Perspektif Konstitusi. (Malang: Setara Press, 2015), hlm.

2 Ahmad Siboy, Alternatif Pemberlakuan Ambang Batas Selisih Suara dalam Hukum Acara Penyelesaian Perselisihan Hasil Pemilihan Kepala Daerah Serentak, (Malang: Disertasi UB Malang, 2018), hlm. 59.
}

sedangkan di wilayah yang memiliki distribusi RPH/TPH lebih dari 10 persen adalah Sumatera dengan jumlah 266 $(19,98$ persen $), \quad$ Sulawesi $199 \quad(14,95$ persen), Bali dan Nusa Tenggara 140 (10,52 persen). Kemudian Kalimantan sebanyak 116 (8,72 persen) dan Maluku serta Papua sebanyak 96 RPH/TPH $(7,21$ persen). ${ }^{3}$

Keberadaan RPH berdampingan dengan lingkungan masyarakat, diperlukan pengolahan yang layak dan sesuai aturan perundang-undangan. Pengaturan jaminan perlindungan hukum bagi masyarakat diatur dalam Peraturan Menteri Pertanian Republik Indonesia Nomor 13/Permentan/OT.140/1/2010 tentang Persyaratan Rumah Potong Hewan Ruminansia dan Unit Penanganan Daging (Meat Cutting Plant) (selanjutnya disebut Permentan RPH).

Perlindungan hukum bagi masyarakat secara preventif diakomodir dalam Pasal 8 ayat 1 dan 2 Permentan RPH, yaitu:

“(1) Kompleks RPH harus dipagar, dan harus memiliki pintu yang terpisah untuk masuknya hewan potong dengan keluarnya karkas, dan daging; (2) Bangunan dan tata letak dalam kompleks RPH paling kurang

\footnotetext{
${ }^{3}$ https://www.bps.go.id/publication/2019/11/21/ 2e390b2bad2ac3033105b95c/direktoriperusahaan-pertanian-rumah-potong-hewan-rph---dan-tempat-pemotongan-hewan--tph--2019.html, diakses tanggal 10 November 2020, pukul 10.15 WIB
} 
meliputi: a. bangunan utama; b. area penurunan hewan (unloading sapi) dan kandang penampungan/kandang istirahat hewan; c. kandang penampungan khusus ternak ruminansia betina produktif; $d$. kandang isolasi; e. ruang pelayuan berpendingin (chilling room); f. area pemuatan (loading) karkas/daging; g. kantor administsrasi dan kantor Dokter Hewan; h. kantin dan mushola; i. ruang istirahat karyawan dan tempat penyimpanan barang pribadi (locker)/ruang ganti pakaian. $j$. kamar mandi dan WC; $k$. fasilitas pemusnahan bangkai dan/ata produk yang tidak dapat dimanfaatkan atau insinerator; $l$. sarana penanganan limbah; m. rumah jaga."

Pengelolan limbah secara benar perlu dilakukan karena limbah padat $\mathrm{RPH}$ mempunyai kandungan bahan organik dan nutrien yang tinggi. ${ }^{4}$ Limbah ini tidak dapat langsung diaplikasikan pada tanah sebagai pupuk dalam keadaan segar karena kandungan bahan organiknya belum stabil. ${ }^{5}$ Selain itu, terkandung pula patogen

${ }^{4}$ Castrillon, L., Fernandez-Nava, Y., Maranon, E., Garcia, L., dan Berrueta, J. Anoxic-Aerobik Treatment of The Liquid Fraction of Cattle Manure. Waste Management, Vol. 29, 2009. hal. 761-766. Lihat juga Roy, B.C., Khan, M.R.I., Rahman, M.M., Salleh, M.A.M., Ahsan, A., dan Amin, M.R. 2013. Development of a Convenient Method of Rumen Content Composting. Journal of Animal and Veterinary Advances, Vol. 12, hal. 1439-1444. Lihat juga Ratnawati, R. dan Trihadiningrum, Y. "Slaughterhouse Solid Waste Management in Indonesia". Journal of Biological Researches 19, 2014. 69-73.

${ }^{5}$ Castrillon, L., Fernandez-Nava, Y., Maranon, E., Garcia, L., dan Berrueta, J. Anoxic-Aerobik Treatment of The Liquid Fraction of Cattle Manure. Waste Management, Vol. 29, 2009. hal. 761-766. dan bibit gulma. ${ }^{6}$ Limbah padat RPH tersebut belum dikelola dengan baik, biasanya ditumpuk di tempat terbuka dan ada pula yang langsung dibuang ke Tempat Pemrosesan Akhir (TPA). Hal ini berkontribusi terhadap timbulnya gas rumah kaca (GRK). Tumpukan limbah padat RPH ini menghasilkan emisi gas metana $\left(\mathrm{CH}_{4}\right)$ dan karbondioksida $\left(\mathrm{CO}_{2}\right)$ yang merupakan kontributor utama

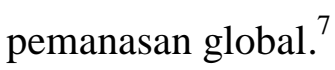

RPH merupakan usaha yang bisa didirikan oleh setiap masyarakat dengan beberapa persyaratan yang harus diperhatikan. Salah satu diantaranya adalah lokasi. Setiap RPH bisa dipastikan menimbulkan limbah yang berbahaya bagi lingkungan terutama yang dapat berdampak langsung maupun tidak langsung bagi masyarakat sekitar. Masyarakat memiliki hak untuk menikmati

${ }^{6}$ Olaniyi, C.O. "Economic Evaluation, Growth Performance and Nutrient Utilization of Rumen Content in The Nutrition of African Catfish (clarias gariepinus) Burchell, 1822. In: Shriver AL (Hrsg.). Proceedings of the Fifteenth Biennial Conference of The International Institute of Fisheries Economics and Trade. International Institute of Fisheries Economics \& Trade, USA, July 13-16, 2010, Montpellier, France. Lihat juga Guo, R., Li, G., Jiang, T., Schuchardt, F., Chen, T., Zhao, Y., dan Shen, Y. 2012. Effect of Aeration Rate, C/N Ratio and Moisture Content on The Stability and Maturity of Compost, Bioresource Technology, Vol. 112, hal. 171-178.

${ }^{7}$ Mackie, K. R dan Cooper, C. D. Landfill gas emission prediction using Voronoi diagrams and importance sampling. Environmental Modelling \& Software, 2009, hal. 1223-1232. 
lingkungan bersih di satu sisi, di sisi lain pengelola RPH juga memiliki hak untuk berusaha. Keduanya tersebut perlu mendapat perhatian dalam bentuk regulasi yang jelas agar hak orang dibatasi dengan kewajiban pihak lain.

Berdasarkan pemaparan diatas, permasalahan yang akan dibahas dalam artikel ini adalah perlindungan hukum bagi masyarakat terhadap pengelolaan limbah rumah potong hewan. Tujuan dari penulisan artikel ini diharapkan mampu memberikan pemahaman akan pentingnya perlindungan hukum bagi masyarakat terhadap pengelolaan limbah rumah potong hewan di Indonesia.

Metode penelitian adalah yuridis normatif. Menggunakan pendekatan undang-undang (statuta approach) dan pendekatan kasus (case approach).

\section{B. Pembahasan}

1. Perlindungan Hukum bagi Masyarakat Perlindungan memiliki kata dasar "lindung" yang mempunyai arti tempat berlindung, hal (perbuatan dan sebagainya), memperlindungi (menjadikan atau menyebabkan berlindung). ${ }^{8}$ Perlindungan juga dapat diartikan

8 Kamus Besar Bahasa Indonesia Pusat Bahasa Departemen Pendidikan Nasional, (Jakarta: PT. Gramedia Pustaka Utama, 2008), hlm. 830. pemberian jaminan atas sesuatu sebagai konsekuensi dari sang pelindung. ${ }^{9}$

Perlindungan hukum menurut Satjipto Rahardjo merupakan hak sebagai kekuasaan yang diberikan oleh hukum kepada seseorang dengan maksud untuk melindungi kepentingan seseorang tersebut. ${ }^{10}$ Perlindungan hukum juga tercermin dari pendapat Sunaryati Hartono, bahwasanya hukum dibutuhkan untuk mereka yang lemah dan belum kuat secara sosial, ekonomi dan politik untuk memperoleh keadilan sosial. ${ }^{11}$

Perlindungan hukum adalah konsep yang tersusun secara universal dari negara hukum. Satjipto Raharjo memaknai perlindungan hukum yaitu suatu perlindungan yang diberikan kepada masyarakat supaya dapat menikmati semua hak-hak yang diberikan oleh hukum serta memberikan sebuah pengayoman terhadap hak asasi manusia yang dirugikan oleh orang lain. ${ }^{12}$

9 Husein Alting, Dinamika Hukum dalam Pengakuan dan Perlindungan Hak Masyarakat Hukum Adat Atas Tanah, (Yogyakarta: Laksbang Pressindo, 2011), hlm. 73.

10 Satjipto Rahardjo, Ilmu Hukum, (Bandung: Alumni, 1986), hlm. 94.

11 Sunaryati Hartono, Politik Hukum menuju Satu Sistem Hukum Nasional, (Bandung: Alumni, 1991), hlm. 55.

${ }^{12}$ Satjipto Rahardjo, Ilmu Hukum, (Bandung: PT. Citra Aditya Bakti, 2000), hlm. 54. 
Hak asasi manusia perlu dilindungi karena sebagai warga negara perlu adanya jaminan hidup. Philipus M. Hadjon memberikan argumentasinya bahwa perlindungan hukum merupakan suatu tindakan untuk melindungi atau memberikan pertolongan kepada subjek hukum melalui perangkat-perangkat hukum. ${ }^{13}$

Prinsip perlindungan hukum terhadap tindakan pemerintah bersumber dari berbagai konsep tentang pengakuan dan perlindungan terhadap hak asasi manusia. Lahirnya konsep perlindungan hukum menurut sejarah merujuk konsep terkait pengakuan dan perlindungan dan mengarah pada peletakan serta pembatasan kewajiban masyarakat dan pemerintah. Pembatasan kewajiban masyarakat dan pemerintah merujuk pada aspek dominan Barat dengan meletakkan dasar hak asasi manusia sebagai hak dan kebebasan secara individu. Sedangkan dari Timur, hak asasi manusia tidak lepas dengan masuknya hak sosial dan ekonomi. Berkaitan dengan hal ini, konsep ini menuai kritik dikarenakan dengan adanya masuknya hak sosial dan

13 Philipus M.Hadjon, Pengantar Hukum Administrasi Indonesia, (Yogyakarta: Gadjah Mada University, 2011), hlm. 10. hak ekonomi dapat melunturkan nilai individualistik. $^{14}$

Nilai yang terkandung dalam hak asasi manusia merupakan harkat dan martabat yang bebas dimiliki setiap individu. Perlindungan hukum merupakan penyempitan arti dari perlindungan. Perlindungan hukum adalah pengejawantahan perlindungan yang diberikan sepenuhnya oleh hukum serta mencakup hak dan kewajiban yang melekat dari manusia selaku subyek hukum dalam berinteraksi dengan sesama manusia dan sekitarnya (lingkungan). Tindakan hukum dapat dilakukan oleh subyek hukum dikarenakan memiliki hak dan kewajiban yang melekat dalam dirinya. $^{15}$

Setiono memberikan pengertian perlidungan hukum yaitu tindakan atau upaya untuk melindungi masyarakat dari perbuatan sewenang-wenang oleh penguasa yang tidak sesuai dengan aturan

\footnotetext{
14 Ummu Hilmy, Pelanggaran dan Perlindungan Hukum Tenaga Kerja Perempuan di Kabupaten Malang, Mimbar Hukum, Volume 23, Nomor 3, (Yogyakarta: Universitas Gadjah Mada, 2011), hlm. 5-6.

${ }^{15}$ C.S.T. Kansil, Pengantar IImu Hukum dan Tata Hukum Indonesia, (Jakarta: Balai Pustaka, 1980), hlm. 102.
} 
hukum dalam mewujudkan ketertiban dan ketentraman $^{16}$.

Ketertiban dan ketenteraman perlu diciptakan dengan cara keikutsertaan semua elemen dalam mewujudkan cita hukum pada negara hukum. Tujuan hukum menurut Gustav Radbruch mencakup tiga aspek dan diperlukan suatu asas prioritas dari ketiga nilai dasar yang menjadi tujuan hukum. Asas prioritas yang dipergunakan oleh Gustav Radbruch yaitu keadilan hukum, kemanfaatan hukum dan kepastian hukum. $^{17}$

Keadilan sosial bagi seluruh rakyat Indonesia merupakan isi dari sila kelima adalah landasan konsep dari pada keadilan yang sejati. Perlindungan hukum bagi masyarakat terhadap pemerintahan bersumber dan bertumpu dari konsep tentang pengakuan serta perlindungan hukum hak asasi manusia. Perlindungan hukum berfungsi melindungi seluruh kepentingan manusia yang dilaksanakan secara berkeadilan. Perlindungan hukum yang terwujud sesuai dengan amanat konstitusi akan mecapai tujuan hukum yang bersifat universal diantaranya ketertiban, ketenteraman, kedamaian,

\footnotetext{
${ }^{16}$ Setiono, Rule of Law (Supremasi Hukum), (Surakarta: Pascasarjanan UNS, 2004), hlm. 3

${ }^{17}$ Muhammad Erwin, Filsafat Hukum, (Jakarta: Raja Grafindo, 2012), hlm. 123.
}

kesejahteraan dan kebahagiaan dalam tata kehidupan bermasyarakat. ${ }^{18}$

Preambule Undang-Undang Dasar Negara Republik Indonesia Tahun 1945 (UUD NRI Tahun 1945) juga secara jelas memberikan payung hukum dengan bunyi "melindungi segenap bangsa Indonesia" yang berarti mencakup adanya perlindungan hukum bagi warga negara.

Perlindungan hukum bagi masyarakat juga sekaligus mencakup melindungi lingkungan yang ada disekitar. Lingkungan hidup berdasarkan Pasal 1 angka 1 Undang-Undang Republik Indonesia Nomor 32 Tahun 2009 tentang Perlindungan dan Pengelolaan Lingkungan Hidup (selanjutnya disebut UU PPLH), sebagai berikut:

"Lingkungan hidup adalah kesatuan ruang dengan semua benda, daya, keadaan, dan makhluk hidup, termasuk manusia dan perilakunya, yang mempengaruhi alam itu sendiri, kelangsungan perikehidupan, dan kesejahteraan manusia serta makhluk hidup lain."

Dasar hukum perlindungan juga selanjutnya diatur dalam Pasal 1 angka 2 UU PPLH, menyatakan:

"Perlindungan dan pengelolaan lingkungan hidup adalah upaya sistematis dan terpadu yang dilakukan untuk melestarikan fungsi lingkungan hidup dan mencegah terjadinya

18 Zainal Asikin, Pengantar IImu Hukum, (Jakarta: Rajawali Pers, 2012). hlm. 19. 
pencemaran dan/atau kerusakan lingkungan hidup yang meliputi perencanaan, pemanfaatan, pengendalian, pemeliharaan, pengawasan, dan penegakan hukum."

Tujuan dari perlindungan dan pengelolaan lingkungan hidup juga tertuang dalam Pasal 3 huruf a dan b, “ $a$. melindungi wilayah Negara Kesatuan Republik Indonesia dari pencemaran dan/atau kerusakan lingkungan hidup; $b$. menjamin keselamatan, kesehatan, dan kehidupan manusia." Dasar hukum tersebut secara keseluruhan, dapat menciptakan perlindungan hukum terhadap masyarakat secara berkeadilan dan berkepastian serta pengelolaan terhadap limbah padat RHP dilakukan sesuai dengan prosedur dan aturan yang ada.

Perlindungan hukum yang dapat melindungi subyek hukum adalah melalui peraturan perundang-undangan yang berlaku dan dipaksakan pelaksanaannya dengan suatu sanksi. ${ }^{19}$ Perlindungan hukum oleh Philipus M.Hadjon terbagi menjadi dua yaitu preventif dan represif. Perlindungan hukum preventif artinya sangat penting bagi tindak pemerintahan yang didasarkan pada kebebasan

19 Muchsin, Perlindungan dan Kepastian Hukum bagi Investor di Indonesia, (Surakarta: Magister IImu Hukum Program Pascasarjana Universitas Sebelas Maret. bertindak, karena dengan adanya perlindungan hukum preventif menjadikan pemerintah terdorong untuk bersikap hatihati dalam mengambil keputusan yang didasarkan pada diskresi. ${ }^{20}$ Perlindungan hukum represif berarti penanganan perlindungan hukum bagi rakyat oleh Peradilan Umum di Indonesia, termasuk Peradilan Administrasi seandainya merupakan satu-satunya fungsi Peradilan (justitiele functie judicial function). ${ }^{21}$

Masyarakat atau community (masyarakat setempat) merupakan warga sebuah desa, sebuah kota, suku atau suatu negara. Masyarakat setempat adalah suatu kelompok baik besar atau kecil, hidup bersama serta memenuhi kepentingankepentingan hidup bersama. ${ }^{22}$

Masyarakat berasal dari bahasa Arab "syirk" artinya bergaul atau interaksi. ${ }^{23}$ Sedangkan dalam bahasa Inggris "society" berasal dari kata "sociuc" artinya kawan. Masyarakat juga diartikan kesatuan sosial

20 Philipus M.Hadjon, Perlindungan Hukum Bagi Rakyat Indonesia, (Surabaya: Percetakan M2 Print, Edisi Khusus, 2007), hlm 2-3.

${ }^{21}$ Ibid.,

22 Soerjono Soekanto, Sosiologi Suatu Pengantar, (Jakarta: Rajawali, 1990), hlm. 162.

23 Koentjaraningrat, Pengantar Antropologi, (Jakarta: Aksara Baru, 1979), hlm. 157. 
ataupun ikatan-ikatan kasih sayang yang erat. $^{24}$

Masyarakat secara ilmiah terkandung pluralisme didalamnya. Pluralisme merupakan sistem nilai yang memandang secara optimis dalam kemajemukan dan menerima sebaik mungkin kenyataan yang sesungguhnya. ${ }^{25}$ Dinamika yang ada dalam masyarakat menurut Murtadha Mutahhari yang menyebabkan gerak maju masyarakat dan merupakan suatu cara yang terungkap sebagai pemikiran tertentu. Kemudian beberapa faktor yang mempengaruhi kemajuan masyarakat diantaranya: ras atau keturunan tertentu, lingkungan, genius atau memiliki kemampuan istimewa, ekonomi, takdir dan pendidikan. ${ }^{26}$

Perlindungan hukum bagi masyarakat terkait pengelolaan limbah RPH di Indonesia adalah perlindungan secara legal yang menyangkut semua hak yang melekat pada warga negara terutama di sini adalah setiap warga negara Indonesia dan lingkungan sekitanya. Terdapat beberapa regulasi sebagai bentuk perlindungan hukum bagi masyarakat terhadap limbah

\footnotetext{
${ }^{24}$ M. Munandar Soelaiman, IImu Sosial Dasar Teori dan Konsep IImu Sosial, (Bandung: Eresco, tt), hlm.63

${ }^{25}$ Ruslani, "Cak Nur, Islam dan Pluralisme" dalam Pluralisme Agama, Kerukunan dan Keragaman, (Jakarta: PT. Gramedia, 2001), hlm. 48.

26 Murtadha Mutahhari, Masyarakat dan Sejarah, (Bandung: Mizan, 1986), hlm. 208.
}

RPH. Diantaranya dalam UU No. 41 Tahun 2014 tentang Perubahan atas Undang-Undang Nomor 18 Tahun 2009 Tentang Peternakan dan Kesehatan Hewan dan Peraturan Menteri Pertanian Nomor $\quad$ 13/Permentan/Ot.140/1/2010 tentang Persyaratan Rumah Potong Hewan Ruminansia Dan Unit Penanganan Daging (Meat Cutting Plant). Kedua regulasi tersebut secara tidak langsung sebagai bentuk perlindungan hukum preventif.

2. Pengelolaan Limbah Rumah Potong Hewan di Indonesia

Pengelolaan limbah atau sarana penanganan limbah RPH diatur dalam Pasal 22 Permentan RPH, adalah:

"Sarana penanganan limbah harus memenuhi persyaratan: a. memiliki kapasitas sesuai dengan volume limbah yang dihasilkan; $b$. didisain agar mudah diawasi, mudah dirawat, tidak menimbulkan bau dan memenuhi persyaratan kesehatan lingkungan; $c$. sesuai dengan rekomendasi upaya pengelolaan lingkungan (UKL) dari Dinas yang membidangi fungsi kesehatan lingkungan."

Fasilitas dalam pemusnahan produk atau bangkai sebagai sarana untuk tidak menimbulkan pencemaran juga diatur pada Pasal 21 Permentan RPH, adalah:

"Fasilitas pemusnahan bangkai dan/atau produk yang tidak dapat dimanfaatkan atau insinerator harus memenuhi persyaratan paling kurang sebagai berikut: a. dibangun dekat dengan kandang isolasi; $b$. dapat 
memusnahkan bangkai dan/atau produk yang tidak dapat dimanfaatkan secara efektif tanpa menimbulkan pencemaran lingkungan; c. didisain agar mudah diawasi dan mudah dirawat serta memenuhi persyaratan kesehatan lingkungan."

Kesehatan lingkungan akan terdampak jika limbah padat RPH ditumpuk ditempat terbuka karena akan menimbulkan gas rumah kaca (GRK). Limbah padat RPH yang ditimbun di tempat pemrosesan akhir (TPA) akan mengalami dekomposisi dan menghasilkan emisi gas $\mathrm{CH}_{4}$ dan $\mathrm{CO}_{2}$ yang dapat menyebabkan pemanasan global.

RPH menyebabkan terjadinya pemanasan global karena adanya pengelolaan limbah padat yang berasal dari aktivitas pemotongan hewan yang terdiri atas kotoran sapi, isi rumen, dan rumput sisa pakan ternak. RPH Pegirian salah satu contoh RPH terbesar yang ada di Kota Surabaya. Berdasarkan data ${ }^{27}$ Dinas Peternakan Provinsi Jawa Timur, produksi daging selama beberapa tahun meningkat, diantaranya data terakhir tahun 2018, sebagian hasil produksi daging yang dihasilkan diantaranya : sapi potong 11.010.723 kg, sapi perah $1.554 .000 \mathrm{~kg}$, kambing $446.025 \mathrm{~kg}$, domba $206.360 \mathrm{~kg}$, babi $2.485 .645 \mathrm{~kg}$, ayam buras 1.040 .430

\footnotetext{
${ }^{27}$ http://disnak.jatimprov.go.id/web/data/datast atistik/statistikproduksi, diakses 11 Desember 2020 pukul 15.30 WIB
}

$\mathrm{kg}$, ayam petelur $1.334 .742 \mathrm{~kg}$, ayam pedaging $49.800 .902 \mathrm{~kg}$, dan itik 479.745 $\mathrm{kg}$. Berdasarkan data tersebut, limbah yang dihasilkan RPH akan meningkat dengan jumlah produksi daging yang dihasilkan.

Hanks $^{28}$ dan Porteous ${ }^{29}$ menyatakan bahwa kontribusi relatif terhadap efek GRK (gas $\mathrm{CH}_{4}$ ) yang bersumber dari peternakan sapi adalah 15-20\%. Gas $\mathrm{CH}_{4}$ menyebabkan pemanasan global yang cukup signifikan, walaupun jumlahnya di atmosfer relatif rendah. ${ }^{30}$

Menurut Porteous ${ }^{31}$, gas $\mathrm{CH}_{4}$ memiliki efek GRK 20-30 kali lebih besar dibandingkan dengan gas $\mathrm{CO}_{2}$. Gas $\mathrm{CO}_{2}$ bersifat memantulkan kembali gelombang pendek dari bumi, sehingga mengakibatkan suhu dipermukaan menjadi naik. $^{32}$

Perubahan suhu dipermukaan bumi yang naik itulah dampak dari adanya

28 Hanks, S. Ecology and the Biophere. Florida: St. Luice Press, 1996.

${ }^{29}$ Porteous, A. Dictionary of Environmental Science and Technology, 2nd ed. New York: John Wiley and Sons, 1992.

30 Mor, S., Ravindra, K., Visscher, A. D., Dahiya, R.P., Chandra, A. Municipal solid waste characterization and its assessment for potential methane generation: A case study. Science of the Total Environment 371, 2006, hlm. 1-10.

${ }^{31}$ Porteous, A. Dictionary of Environmental Science and Technology, 2nd ed. New York: John Wiley and Sons, 1992.

32 Samiaji T. Emisi $\mathrm{CO}_{2}$ dari Penggunaan Energi. Lingkungan Tropis, Edisi Khusus Agustus, 2007. hlm. 215-224. 
pengelolaan limbah RPH secara tidak tepat. Oleh karena itu pentingnya pengelolaaan dan perlindungan hukum bagi masyarakat agar manusia dan keseluruhan elemen lingkungan hidup dalam jangka panjang tetap lestari.

Pengelolaan RPH di Indonesia dibedakan berdasarkan beberapa jenis. Perlu dipahami bahwa usaha pemotongan hewan dibagi menjadi 3 (tiga) jenis, yang diatur dalam Pasal 40 ayat (1) sampai ayat (4) Permentan RPH, sebagai berikut:

“(1) Berdasarkan pola pengelolaannya, usaha pemotongan hewan dan/atau penanganan daging dibedakan menjadi 3 (tiga) jenis: a. Jenis I: RPH dan/atau milik pemerintah daerah yang dikelola oleh pemerintah daerah dan sebagai jasa pelayanan uтu; $b$. Jenis II: RPH dan/atau UPD milik swasta yang dikelola sendiri atau dikerjasamakan dengan swasta lain; c. Jenis III: RPH dan/atau UPD milik pemerintah daerah yang dikelola bersama antara pemerintah daerah dan swasta.

(2) RPH dan/atau UPD dengan pola pengelolaa Jenis II dan Jenis III sebagaimana dimaksud pada ayat (1) huruf $b$ dan huruf $c$, selain menyelenggarakan kegiatan pemotongan ternak milik sendiri harus memberikan jasa pelayanan pemotongan dan/atau penanganan daging bagi masyarakat yang membutuhkan.

(3) Berdasarkan kelengkapan fasilitas proses pelayuan (aging) karkas, usaha pemotongan hewan dibedakan menjadi 2 (dua) kategori: a. Kategori I: usaha pemotongan hewan di RPH tanpa fasilitas pelayuan karkas, untuk menghasilkan karkas hangat; $b$.
Kategori II: usaha pemotogan hewan di RPH dengan fasilitas pelayuan karkas, untuk menghasilkan karkas dingin (chilled) dan/atau beku (frozen).

(4) Bagi usaha pemotongan kategori II sebagaimana dimaksud pada ayat (3) huruf b harus dilengkapi dengan fasilitas rantau dingin hingga ke tingkat konsumen."

Pengelolaan limbah RPH disetiap daerah di Indonesia diperlukan instrumen ekonomi lingkungan hidup untuk menjamin keberlangsungan hidup manusia dan sekitar. Dasar hukum yang mengatur Instrumen Ekonomi Lingkungan Hidup yaitu terdapat pada Pasal 42 ayat (1) dan (2) serta Pasal 43 ayat (1), (2), dan (3) UU PPLH, yang menyatakan:

"Pasal 42. Ayat (1) Dalam rangka melestarikan fungsi lingkungan hidup, Pemerintah dan pemerintah daerah wajib mengembangkan dan menerapkan instrumen ekonomi lingkungan hidup. Ayat (2) Instrumen ekonomi lingkungan hidup sebagaimana dimaksud pada ayat (1) meliputi: a.perencanaan pembangunan dan kegiatan ekonomi; b.pendanaan lingkungan hidup; dan c.insentif dan/atau disinsentif."

"Pasal 43. Ayat (1) Instrumen perencanaan pembangunan dan kegiatan ekonomi sebagaimana dimaksud dalam Pasal 42 ayat (2) huruf a meliputi: a.neraca sumber daya alam dan lingkungan hidup; b.penyusunan produk domestik bruto dan produk domestik regional bruto yang mencakup penyusunan sumber daya alam dan kerusakan lingkungan hidup;c.mekanisme kompensasi/imbal jasa lingkungan hidup antardaerah; 
dan d. internalisasi biaya lingkungan hidup. Ayat (2) Instrumen pendanaan lingkungan hidup sebagaimana dimaksud dalam Pasal 42 ayat (2) huruf $b$ meliputi: a.dana jaminan pemulihan lingkungan hidup; b.dana penanggulangan pencemaran dan/atau kerusakan dan pemulihan lingkungan hidup; dan c.dana amanah/bantuan untuk konservasi. Ayat (3) Insentif dan/atau disinsentif sebagaimana dimaksud dalam Pasal 42 ayat (2) huruf $c$ antara lain diterapkan dalam bentuk: a.pengadaan barang dan jasa yang ramah lingkungan hidup; b.penerapan pajak, retribusi, dan subsidi lingkungan hidup; c.pengembangan sistem lembaga keuangan dan pasar modal yang ramah lingkungan hidup; d.pengembangan sistem perdagangan izin pembuangan limbah dan/atau emisi; e.pengembangan sistem pembayaran jasa lingkungan hidup; f.pengembangan asuransi lingkungan hidup; g.pengembangan sistem label ramah lingkungan hidup; h.sistem penghargaan kinerja di bidang perlindungan dan pengelolaan lingkungan hidup; i.ketentuan lebih lanjut mengenai instrumen ekonomi lingkungan hidup sebagaimana dimaksud dalam Pasal 42 dan Pasal 43 ayat (1) sampai dengan ayat (3) diatur dalam Peraturan Pemerintah."

Pengelolaan lingkungan hidup dalam hal ini mencakup pengelolaan RPH yang didalamnya akan menjadi kesinambungan bernilai kebermanfaat apabila proses pengelolaan limbah RPH dapat dilakukan secara benar. Pengelolaan RPH yang benar dan didukung dengan adanya pengawasan serta memberikan punishment untuk para pengelola RPH akan berkontribusi pada lingkungan yang sehat.

Lingkungan yang sehat akan tercipta dengan terlaksananya tahapan prosedur secara tertata. Untuk setiap pengelolaan dasar hukumnya telah diatur dalam Pasal 4 UU PPLH, yaitu:

$\begin{array}{lrr}\text { "Perlindungan } & \text { dan } & \text { pengelolaan } \\ \text { lingkungan } & \text { hidup } & \text { meliputi: } \\ \text { a.perencanaan; } & \text { b.pemanfaatan; } \\ \text { c.pengendalian; } & \text { d.pemeliharaan; } \\ \text { e.pengawasan; } & \text { dan } & \text { f.penegakan } \\ \text { hukum." } & & \end{array}$

Setiap tahapan perlindungan dan pengelolaan yang dijalankan oleh seluruh RPH di Indonesia sesuai aturan hukum yang berlaku, maka akan berkurang dan tidak akan timbul gas rumah kaca (GRK). Tumpukan limbah padat RPH yang menghasilkan emisi gas metana $\left(\mathrm{CH}_{4}\right)$ dan karbondioksida $\left(\mathrm{CO}_{2}\right)$ merupakan kontributor utama pemanasan global.

Berdasarkan pengelolaan RPH dan juga berdampak pada limbah RPH berdasarkan kategori, maka perlindungan bagi masyarakat mutlak diperlukan. Perlindungan hukum telah diatur sedemikian lengkap dan teratur untuk sebagai rambu bahwa penyelenggaraan RPH dan pengelolaan limbah perlu disiapkan sesuai dengan jenis kategori. 


\section{Kesimpulan}

Kesimpulan dari pembahasan adalah perlindungan hukum bagi masyarakat terhadap pengelolaan limbah rumah potong hewan merupakan kewajiban negara untuk memberikan jaminan atas keselamatan, kesehatan, dan kehidupan yang layak kepada setiap manusia dan lingkungannya.

Pengelolaan limbah rumah potong hewan di Indonesia perlu dilakukan secara sistematis seperti adanya perencanaan, pemanfaatan, pengendalian, pemeliharaan, pengawasan, dan penegakan hukum untuk mencegah terjadinya pencemaran terhadap lingkungan hidup dan dapat membuat lestari lingkungan hidup.

Pemahaman pentingnya perlindungan hukum bagi masyarakat terhadap pengelolaan limbah $\mathrm{RPH}$ di Indonesia akan mendorong proses pengelolaan sampah secara terpadu dan sistematis yang berorientasi pada reduksi pengolahan sampah untuk produk daur ulang agar berguna dalam mengurangi emisi gas rumah kaca (GRK).

\section{Daftar Pustaka}

\section{Buku}

C.S.T. Kansil, Pengantar Ilmu Hukum dan Tata Hukum Indonesia, Jakarta: Balai Pustaka, 1980.
Hanks, S. Ecology and the Biophere. Florida: St. Luice Press, 1996.

Husein Alting, Dinamika Hukum dalam Pengakuan dan Perlindungan Hak Masyarakat Hukum Adat Atas Tanah, Yogyakarta: Laksbang Pressindo, 2011.

Kamus Besar Bahasa Indonesia Pusat Bahasa Departemen Pendidikan Nasional, Jakarta: PT. Gramedia Pustaka Utama, 2008.

Koentjaraningrat, Pengantar Antropologi, Jakarta: Aksara Baru, 1979.

Mackie, K. R dan Cooper, C. D. Landfill gas emission prediction using Voronoi diagrams and importance sampling. Environmental Modelling \& Software: 2009.

Muhammad Erwin, Filsafat Hukum, Jakarta: Raja Grafindo, 2012.

Murtadha Mutahhari, Masyarakat dan Sejarah, Bandung: Mizan, 1986.

M. Munandar Soelaiman, Ilmu Sosial Dasar Teori dan Konsep Ilmu Sosial, Bandung: Eresco, tt.

Philipus M.Hadjon, Pengantar Hukum Administrasi Indonesia, Yogyakarta: Gadjah Mada University, 2011.

Philipus M. Hadjon, Perlindungan Hukum Bagi Rakyat Indonesia, Surabaya: Percetakan M2 Print, Edisi Khusus, 2007.

Porteous, A. Dictionary of Environmental Science and Technology, 2nd ed. New York: John Wiley and Sons, 1992.

Ruslani, "Cak Nur, Islam dan Pluralisme" dalam Pluralisme Agama, 
Kerukunan dan Keragaman, Jakarta: PT. Gramedia, 2001.

Samiaji T. Emisi $\mathrm{CO}_{2}$ dari Penggunaan Energi. Lingkungan Tropis, Edisi Khusus Agustus: 2007.

Satjipto Rahardjo, Ilmu Hukum, Bandung: PT. Citra Aditya Bakti, 2000.

Satjipto Raharjo, Ilmu Hukum, Bandung : Alumni, 1986.

Soerjono Soekanto, Sosiologi Suatu Pengantar, Jakarta: Rajawali, 1990.

Sunaryati Hartono, Politik Hukum menuju Satu Sistem Hukum Nasional, Bandung: Alumni, 1991.

\section{Karya Ilmiah}

Ahmad Siboy, Alternatif Pemberlakuan Ambang Batas Selisih Suara dalam Hukum Acara Penyelesaian Perselisihan Hasil Pemilihan Kepala Daerah Serentak, Malang: Disertasi UB Malang, 2018.

Castrillon, L., Fernandez-Nava, Y., Maranon, E., Garcia, L., dan Berrueta, J. Anoxic-Aerobik Treatment of The Liquid Fraction of Cattle Manure. Waste Management, Vol. 29, 2009.

Guo, R., Li, G., Jiang, T., Schuchardt, F., Chen, T., Zhao, Y., dan Shen, Y. Effect of Aeration Rate, C/N Ratio and Moisture Content on The Stability and Maturity of Compost, Bioresource Technology, Vol. 112, 2012.

Muchsin, Perlindungan dan Kepastian Hukum bagi Investor di Indonesia, Surakarta: Magister Ilmu Hukum
Program Pascasarjana Universitas Sebelas Maret, 2003.

Mor, S., Ravindra, K., Visscher, A. D., Dahiya, R.P., Chandra, A. Municipal solid waste characterization and its assessment for potential methane generation: A case study. Science of the Total Environment 371, 2006.

Olaniyi, C.O. "Economic Evaluation, Growth Performance and Nutrient Utilization of Rumen Content in The Nutrition of African Catfish (clarias gariepinus) Burchell, 1822. In: Shriver AL (Hrsg.). Proceedings of the Fifteenth Biennial Conference of The International Institute of Fisheries Economics and Trade. International Institute of Fisheries Economics \& Trade, USA, July 1316, 2010.

Ratnawati, R. dan Trihadiningrum, Y. "Slaughterhouse Solid Waste Management in Indonesia". Journal of Biological Researches 19, 2014.

Roy, B.C., Khan, M.R.I., Rahman, M.M., Salleh, M.A.M., Ahsan, A., dan Amin, M.R. Development of a Convenient Method of Rumen Content Composting. Journal of Animal and Veterinary Advances, Vol. 12, 2013.

Setiono, Rule of Law (Supremasi Hukum), Surakarta: Pascasarjanan UNS, 2004.

Ummu Hilmy, Pelanggaran dan Perlindungan Hukum Tenaga Kerja Perempuan di Kabupaten Malang, Mimbar Hukum, Volume 23, Nomor 3, Yogyakarta: Universitas Gadjah Mada, 2011.

Zainal Asikin, Pengantar Ilmu Hukum, Jakarta: Rajawali Pers, 2012. 


\section{Peraturan Perundang - Undangan}

Undang-Undang Dasar Negara Republik Indonesia Tahun 1945.

Undang-Undang Republik Indonesia Nomor 32 Tahun 2009 tentang Perlindungan dan Pengelolaan Lingkungan Hidup

Peraturan Menteri Pertanian Republik Indonesia Nomor 13/Permentan/OT.140/1/2010 tentang Persyaratan Rumah Potong Hewan Ruminansia dan Unit Penanganan Daging (Meat Cutting Plant).

\section{Website}

https://www.bps.go.id/publication/2019/11 /21/2e390b2bad2ac3033105b95c/dir ektori-perusahaan-pertanian-rumahpotong-hewan--rph---dan-tempatpemotongan-hewan--tph--2019.html, diakses 10 November 2020, pukul 10.15 WIB

http://disnak.jatimprov.go.id/web/data/data statistik/statistikproduksi, diakses tanggal 11 December 2020, pukul 15.30 WIB. 